\title{
Obscuritat i elevació d'enteniment en l'obra de Ramon Llull
}

\author{
Jaume Medina \\ Universitat Autònoma de Barcelona
}

Com ja he exposat en una altra banda ${ }^{1}$, Ramon Llull dóna, en la seva Retòrica nova, una gran importància a les semblances o exemples i als proverbis. Els uns i els altres ocupen la major part del segon capítol del seu tractat, que l'autor dedica a l'examen de la bellesa: hàbilment presentats mitjançant el lligam del locus amoenus, formen els tòpics de què l'autor se serveix per a l'exposició de les seves doctrines filosòfiques i teològiques i alhora per a l'embelliment del conjunt del discurs.

Diu Ramon Llull que una de les condicions perquè el discurs sigui bell $\mathrm{i}$ adornat és que tingui bells exemples intercalats en els llocs adients. Aquests eximplis, anomenats també semblances, poden anar referits a les coses naturals (espirituals — com Déu i els àngels- o corporals — com el cel, la terra i els animals-) o a les morals (les virtuts i els vicis). Es troben escampats per totes les obres lul-lianes i solen anar seguits de la seva explicació:

En una terra - diu l'ermità del Libre de meravelles — havia un rei qui molt amava justícia; e sobre sa cadira reial havia fet un braç d'home qui era de peira, e en sa mà tenia una espasa, e en la punta de l'espasa estava un cor qui era d'una peira vermella, a significança que lo cor del rei havia volentat a moure lo braç que mogués l'espasa, que justícia significava. E esdevenc-se que per una gran serpent lo palau fo jaquit, e null hom no hi poc habitar. E un jorn entrà un sanct hom en aquell palau, lo qual cercava on pogués fer penitència $\mathrm{e}$ contemplar Déu, e viu lo braç e l'espasa, e lo cor qui en la espasa estava. Molt se meravellà d'açò que lo braç e l'espasa, e lo cor significava; emperò tan longament cogità en aquella figura, d'entrò que apercebé ço per què aquella figura era feta.

- Sènyer — dix Fèlix-, aquesta semblança que vós diets, què significa?—. —Bell amic — dix l'ermità-, considerar devets que aquest món és per alcuna ocasió de bé; car sens ocasió de bé no poria ésser tan bell món com

1 Vegeu: Jaume Medina, Una introducció a l'obra catalana de Ramon Llull. «Notandum». São Paulo/Porto. Ano XII - N. 20 mai-ago 2009, p. 15-26. http://www.hottopos.com 
aquest. E, si Déus res no era, seria lo món per ocasió de mal, car més seria de mal que de bé. E car bé se cové ab ésser, e mal se cové ab no ésser, és semblant que ço per què lo món és bo, és Déu; e açò per què lo món seria major en mal que en bé, seria no ésser Déu, sens l'ésser del qual tot quant és seria debades, e seguir-s'hia que bé fos per ço que fos mal, e mal seria per si mateix, e seria la fi de bé, e açò és inconvenient; per lo qual és declarat Déus ésser- ${ }^{2}$.

De vegades, però, les semblances són més que difícils i de bones a primeres semblen no tenir res a veure amb les preguntes de Fèlix. Això és el que ocorre, per exemple, al capítol XIV del Libre de meravelles, on el curiós obedient es queixa de l'aparent manca de connexió amb el tema que es tracta: en aquest cas, la definició de la naturalesa de l'àngel. Vet aquí com es desenrotlla la primera part del capítol dessusdit:

—Sènyer —dix Fèlix—, l'ésser de l'àngel, què és? ¿Ne qual cosa és ço que àngel és?- . E l'ermità dix estes paraules: -Era un rei que no sabia què era rei ne ofici de rei. Aquell rei féu un gran falliment contra ofici de rei, per lo qual falliment se seguí molt gran damnatge a tota sa terra e a moltes d'altres terres. Molt fo irat lo rei d'aquell falliment que feit havia, lo qual no poc adobar: tant de dan se n'era seguit. Molt se meravellà lo rei com tan de damnatge se n'era seguit, d'aquella errada que feta havia, e maldix son pare qui l'havia engendrat, e sa mare qui l'havia concebut, com no li havien mostrada en sa joventut tanta de ciència que·n sabés què és ofici de rei, e què és rei; e car l'havien posat en ofici lo qual no sabia què s'era, maldeïa son pare e sa mare.-

Molt fortment se meravellà Fèlix d'aquella semblança que l'ermità deïa, car no li era vijares que faés al propòsit segons lo qual ell demanava àngel què era. L'ermità conec que Fèlix se meravellava e que no entenia la semblança que dita li havia, e dix aquesta semblança a Fèlix: - En un gran monestir estava un sanct religiós qui de sancta vida sobrepujava tots los altres religioses qui estaven en aquell monestir. Per l'alta vida que aquell sanct hom havia, havia privilegi sobre tots los altres d'estar tot sol en una cambra en què menjava, e jaïa, e a Déu pregava totes les vegades que-s volia. Esdevenc-se que un jorn ell se meravellà per què hom veïa, e oïa, e odorava, e gustava, e sentia. Estant aquell sanct hom en aquesta consideració, un rei venc veser aquell sanct hom, per la gran fama que havia oïda de la sanctedat d'aquell sanct hom, sí que lo rei viu aquell sanct religiós pobrement vestit, e viu lo pobre lit en què lo religiós jaïa; e l'abat d'aquell monestir loà molt lo sanct hom de l'aspra vida que soferia en menjar, jaer e vestir, e en les altres coses per què lo cors és en aflicció. Molt se meravellà, lo sanct hom de l'abat qui·l loava, car loant ell, acusava si mateix e son orde contra l'alta penitència a la qual son orde era establit per los sancts hòmens qui són passats, los quals foren hòmens de molt gran penitència.

Estant que aquell sanct hom se meravellava de l'abat qui.l loava, lo rei dix a l'abat estes paraules: «Natura és d'aquestes coses corporals que vivifiquen los

${ }^{2}$ Ramon Llull, Llibre de meravelles. Dins: Ramon Llull, Obres essencials, Barcelona (Editorial Selecta) 1957, p. 320. (D'ara endavant, citaré aquesta obra com OE, I, p....). 
senys corporals com hom n'usa, segons la manera per la qual hom ha plasers sensuals; e per açò los hòmens mundans fan a la vista bells palaus e belles vestedures, e volen veser coses belles, per ço que la vista haja major plaser on pus ço que veuen és bell. Açò mateix fan los hòmens mundans als altres senys corporals, car per raó de l'oir volen oir paraules de loar, e per l'odorar volen nobles odors, e per lo gustar volen menjars delicats e volen beure nobles vins, e per lo palpar volen haver molls draps, molls lits e molls vestiments, e es mouen a carnals delits». En les paraules que el rei recontava de l'ofici de la sensitiva, conec lo sanct hom ço que era la virtut per què-ls hòmens senten les coses sensibles, ço és saber, que la virtut sensitiva ama usar, per natura, en semblants coses de si mateixa en grans delits e benanances; car natural cosa és que tota cosa ame sa semblança en gran benanança.

Fins aquí les respostes de l'ermità a la pregunta de Fèlix. Ara bé: tal com hem pogut veure, aquest, ja després de la primera resposta havia expressat la seva perplexa meravella. Per això, després de la segona no es podia estar d'insistir obertament:

- Sènyer [...], molt me meravell de vostres eximplis, car vijares m'és que no fassen res al propòsit de ço que jo us deman-.

Tanmateix, sense immutar-se, el sant ermità li responia:

—Bell amic [...], cientment vos faç aitals semblances per ço que vostre enteniment exalcets a entendre; car on pus escura és la semblança, pus altament entén l'enteniment qui aquella semblança entén- ${ }^{3}$.

I és això el que autènticament meravella de tot aquest diàleg sostingut entre l'ermità i Fèlix, perquè tan sorprenent com la perplexitat del rodamón és la resposta del religiós, que, sense fer cap mena de concessions a la facilitat i mantenint-se al cim de la seva elevació, confessa haver posat aquelles semblances a consciència, per tal de motivar també Fèlix a elevar el seu enteniment a entendre. I, a la fi, l'ermità rebla el seu parlament amb un aparent joc de paraules que, tanmateix, no té res de lúdic.

Ara bé: Ramon Llull no improvisava pas aquest pensament ni tampoc la construcció sintàctica de què se servia per a expressar-lo. En efecte, la pròtasi en què parla d' «exalçar l'enteniment a entendre», compta, com podrem veure tot seguit, amb una llarga i fecunda tradició en les obres del savi mallorquí, igualment com la construcció apodòtica que diu «car on pus escura és la semblança..., etc.». No és el meu propòsit resseguir ara totes i cada una de les ocasions anteriors al Llibre de meravelles (1288-1289) en què l'autor se serveix d'aquesta expressió. Tanmateix, deu ser una idea concebuda des dels primers moments que es posava a escriure, perquè ja la trobem formulada de maneres diverses en les seves primeres obres, entre les quals figuren la Doctrina pueril (1274-1276) i el Llibre d'oracions i contemplacions de l'enteniment (1274-1276), així com també en al-

3 OE, I, p. 346. 
tres obres posteriors, com el Llibre d'Evast e d'Aloma e de Blaquerna (12761283).

Per començar, ja al Llibre de doctrina pueril, II, 8, parla del mateix llibre, dient que «gens és fet a exalçat enteniment, ans és fet per ço que els enteniments dels infants pusquen esser exalçats a entendre aquest món i Déu». I després, a VI, 8, mostra la manera com l'enteniment s'exalça: «per llum de fe», cosa que repeteix a LII, 3: «per llum de fe s' exalça l'enteniment a entendre»; i encara: «si tu vols haver subtil enteniment, no sies increable, $i$ criu, per ço que pusca ton enteniment pujar tan alt que entena ço que la fe il.lumina»; i a LXXV, 7 torna a dir que «l' humanal enteniment per llum de fe s'exalça a entendre Déu». Qui vol conèixer Déu ha de tenir fe: per no haver-ne tinguda, no el van poder conèixer els grans filòsofs grecs; així ho manifesta a LXXV, 7: «Aristòtil i Plató i los altres filosofs qui volien haver coneixença de Déu sens fe no pogren, fill, pujar tan alt llur enteniment que poguessen haver declaradament coneixença de Déu ni de ses obres ni de ço per què hom va a Déu». És a aquest coneixement de Déu que impulsa l'autor en el capítol XXXI, 9. Diu: «Per açò te don de consell que tu aitant con pusques sobre totes coses exalces ton enteniment en honrar, lloar i conèixer aquell per qui tu tens $i$ has ton enteniment, ço és Déus gloriós sant Esperit». L'enteniment exalçat per la fe puja a entendre coses més elevades que les que hom pot percebre per mitjà dels cinc sentits corporals i fins per mitjà de la fantasia i de la imaginació. Això és el que diu a XXV, 9 (sobre els sentits): «l'exalçament que el teu enteniment pren per llum de fe sobre los $\cdot V \cdot$ senys corporals, sobrepuja majors coses entendre per la virtut de Déu que per les obres naturals ni per los senys corporals; i també a LXVIII, 6 (sobre la fantasia): «Natural cosa és que hom amb los ulls coporals veja lo cel i les esteles, la mar i les terres i les altres coses, i amb les orelles oja les veus i els sons, i amb lo nas odor les odors, i així dels altres senys corporals; i natural cosa és que l'ànima amb la imaginativa prenga tot ço que prenen los senys corporals, $i$ que ho do a l'humanal enteniment, en la fantasia qui és entre lo front i el tòs, $i$ que l'enteniment se lleu a ensús sobre la fantasia a entendre ço que li és ofert de la noblesa i la grandesa de Déu»; i, encara, a LXXXV, 5 (sobre la imaginació): «Sàpies, fill, que l'ànima amb la imaginació pren i ajusta en comú tot ço que li oferen los cinc senys corporals, veent, oent, odorant, gustant, sintent; i ofer-ho en la fantasia a l'enteniment; enaprés l'enteniment puja més a ensús en entendre Déu i àngels $i$ les coses intel-lectuals, les quals la imaginativa no pot imaginar»; i a LXXXV, 8 (igualment sobre la imaginació): «Amable fill, molt hom cau en dubte i en error con cuida imaginar les coses espirituals i intel-lectuals, les quals no poden esser imaginades; car enaixí con los ulls han un ofici i les orelles n'han altre, enaixí la imaginativa ha ofici d'imaginar ço qui és corporal, i l'enteniment que entena ço qui és corporal i qui és espiritual. On, con l'enteniment sia pus alt en virtut que la imaginació, per açò pot entendre ço que la imaginació imagina, i sobrepuja la imaginació, qui no pot imaginar ço qui és de natura intel-lectual».

Hi ha encara dues altres maneres d'exalçar l'enteniment a entendre. Una és la que l'autor exposa a L, 7: «Exalçat és l'humanal enteniment en los hòmens per costumes i per escriptures, i requestes són per los infeels raons i probacions necessàries a mostrar veritat de la fe catòlica; i request és a nosaltres con per gran caritat i fervor treballem en aprendre diverses llenguatges per haver doctrina 
necessària, pus que no som dignes de fer miracles; la qual indignitat havem per defalliment de caritat de fervor, i per la temor que havem en sostenir treballs i mort per amor de Déu». Una altra és la caritat, és a dir, l'amor, tal com ho diu a LIIII, 2: «Amable fill, caritat dóna plaer dels béns i dels mals que hom sosté per amor, i caritat exalça la voluntat a voler grans coses $i$ nobles, $i$ exalça l'enteniment a entendre grans coses $i$ altes, i caritat ajusta home a Déu, i caritat fa donar a Déu grans dons i nobles, i fa perdonar a Déu grans culpes i grans falliments, i caritat fa home consolar de grans dans, i fa los hòmens pobres rics de coratge.

Tanmateix, hi ha homes amb un enteniment més clar i més elevat que altres. Així ho ha volgut Déu mateix. És el que Ramon Llull diu a XXXI, 3: «Enaixí, fill, com tu veus amb los ulls corporals les carreres per on vas, enaixí la tua ànima sap membrar i amar i imaginar i veure amb los ulls de l'enteniment. Enaixí com natura dóna a alguns hòmens pus clara vista que als altres, enaixí lo sant Esperit dóna a alguns hòmens pus clar i pus elevat enteniment que als altres». És a aquests sobretot que cal la llum de la fe. Així ho diu a LII, 3: «Déus ha donades a home dues mans per ço que una mà ajut l'altra; i Déus ha donats a home dos llums, llum de fe i llum d'enteniment; d'on, si hom no pot haver llum d'enteniment, haja llum de fe, i crea ço que no pot entendre. On, aquest llum de fe és necessari, majorment als llauradors $i$ als menestrals $i$ als hòmens qui no han exalçat enteniment, i per aquest llum s'ajuden de les errors i de les temptacions contra los dimonis qui volen a home fer descreure les coses que enteniment no pot entendre».

Finalment, també a la Doctrina pueril Ramon Llull ofereix mitjans per elevar l'enteniment a entendre. A XCI, 19 diu: «¿Vols bé nodrir ton infant? Acostuma sa memòria i son enteniment a cogitar nobles fets, per ço que la voluntat am privadesa de bons hòmens. ¿I vols nodrir l' enteniment de ton fill a esser exalçat i elevat a entendre? Mostra-li ciència divina i natural. I vols que haja molt alt enteniment a entendre subtilment? Mostra-li Art de trobar veritat $i$ lo Llibre de definicions i de començaments i de qüestions. ¿I vols que ton infant am molt Déu? Fé-li membrar i entendre la viltat d'aquest món i la bonesa, grandesa, eternitat, poder, saviesa, amor i les altres virtuts de Déu». On, tal com podem veure, remet a altres obres seves per adquirir l'hàbit de l'elevació de l'enteniment.

També al Llibre d'oracions $i$ de contemplacions de l'enteniment parla Ramon Llull d'aquesta elevació de l'enteniment. Ja a la mateixa invocació diu: «Déu, qui sots primera causa, e nós efectu: per ço, Senyor, que vostres excel-lents dignitats conegudes sien e amades, l' humà enteniment, per vostra virtut, $s^{\prime}$ exalça ab tot son poder a conèixer aquelles, e la volentat les desira amar e servir en l'exaltació de l'enteniment...» I al pròleg: «En la ignorància que l'efectu ha de la primera causa, és mortificada, en la voluntat, caritat, devoció, justícia e contricció, confessió, fortitudo, animositat, e per ço l'enteniment amb tots sos poders s' esforça a pujar entendre les dignitats de son creador». A I, 4: «...e en l'exalçament que jo prenc en ésser certificat vós ésser, s' exalça la voluntat a vós amar e honrar, e la memòria a remembrar e obeir los vostres manaments...». A I, 9: «Molt plac a la volentat ço que li hac respost l'enteniment, e totes tres les potències adoraren e contemplaren Déu molt fortment; e la memòria e la volentat pregaren l'entiment que ell los recomptàs d'altres raons e demostracions a provar Déus ésser, car molt n'havien gran plaer; mas l'enteniment s'escusà dient 
que bastantment eren certificades de la presència de Déu, e per açò fení ses paraules en provar Déus ésser, e començà a recomptar de la bonesa de Déu, per ço que s'exalçàs a entendre molt gran bé, e que la memòria se n' exalçàs e membrar, e la volentat a amar lo bé qui és molt sobirà a tots altres béns». A II, 4: «Exalçà's la memòria a remembrar estes paraules, dient...». A II, 5: «On, com l'enteniment fos davallat per ço que pogués pujar contemplar lo bé increat, adoncs lleixà los objects dejús e pujà prendre los sobirans, entenent com un bé sobirà engendra altre bé, e de abdosos n'ix altre, e tots tresos són bé infinit en unitat e en infinitat de bonesa, granesa, eternitat, poder, e cetera. E l'enteniment e ses sors adoraren e contemplaren la sobirana bonesa de Déu, per la qual fo il-luminada la memòria en membrar e l'enteniment entendre e la volentat amar la manera per la qual santa ànima pot ésser exalçada en adorar e contemplar la bonesa de Déu». A IV, 2: «Con l'enteniment hac satisfet a la volentat, l'enteniment sesforçà a pujar a entendre, e desviàs de la imaginació, e entès que si en l'eternitat de Déu no era qui engendràs scient e amant en bonesa e granesa infinides, hauria's pus fortment eternitat a durar, que saviesa, amor, bonesa e infinitat; e si en saviesa e amor, bonesa e infinitat de granesa, no havia qui engendràs eternal, hauria's en Déu pus fortment bonesa, granesa, amor, que eternitat; e cascuna d'aquestes coses és incovenient. Per lo qual l'enteniment fo exalçat en contemplar e adorar l'eternitat de Déu». A V, 4: «Plaer hac l'enteniment com ses sors lo havien entès, e pujà ensús...» A VI, 1: «Preposà l' humà enteniment pujar a adorar e contemplar la saviesa de Déu, e foren en sa companyia memòria e volentat, per ço que la memòria membràs e la volentat amàs ço que l'enteniment entendria de la saviesa de Déu. Com l'enteniment fon pujat molt alt, la volentat li dix que pujàs més ensús, e l'enteniment respòs que no poria més ensús pujar; e adoncs la volentat hac fe que l'enteniment pogués més entendre que no havia entès de la saviesa de Déu; e per açò l'enteniment pujà més ensús, e dix a la volentat e a la memòria, de la saviesa de Déu, ço que entenia, dient aquestes paraules». A VII, 6: «Assats són pagada [la voluntat] de ço que recomptes, e prec-te que recomptes de l'encarnació del Fill de Déu algunes paraules, e si em pots donar manera com l'encarnació pusca amar e ton entendre exalçar més ma animositat en Déu amar e ses obres». A VIII, 2: «Sotsposà voluntat Déus ésser, e haver Déus perfecció en si mateix e en sa obra, la qual suposició és per ço que l'enteniment cercàs demostracions per les quals provàs Déus ésser, en la qual provació fos exalçat entendre». I a X, 9: «Mas la imaginació mortificà la volentat, dient a l'enteniment que segons que ell deïa, se convenia seguir que Déus s'encarnàs en molts hòmens infinidament en nombre, per ço que la virtut d'aquells ne fos més exalçada en Déu».

Finalment, al Llibre d'Evast e d'Aloma e de Blaquerna, trobem també ressons d'aquest pensament. Així, al capítol XXXIX, diu: «On, dementre que l'abadessa deïa subtilment aquestes paraules, una dona dix a l'abadessa que no era leguda cosa que a fembres fossen dites tan subtils paraules. E l'abadessa respòs dient que, pus l'enteniment les podia entendre, covinent cosa era que la volentat volgués que l'enteniment se n' exalçàs a entendre, e que mills ne pogués la volentat contemplar e entendre Déu e ses obres» ${ }^{4}$. Igualment, al capítol XLIII:

${ }^{4}$ OE, I, p. 168. 
«Car aitant com l'enteniment pot pujar més a ensús per entendre los articles, d'aitant pusc jo sobrepujar més a ensús sobre l'enteniment, e creu ço que ell no pot entendre» ${ }^{5}$. També, al capítol LIV: «Gran gràcia fa Déus a home com li dóna vista corporal, per ço que-ls ulls de la pensa obeesquen a açò que la vista corporal significa, en les creatures veïbles, la noblea del creador; mas major gràcia fa Déus a volentat qui obeeix als ulls de l'enteniment qui entén aquelles coses a les quals la volentat deu ésser pus obedient. Car volentat obedient a aquell qui no ha enteniment, és semblant al meu estament; e si enteniment degués ésser obedient a volentat, non fóra intel-ligència en tan gran honrament, si doncs volentat no li fos pus fortment obedient». I més endavant, al mateix capítol, diu que «pus noble cosa era en enteniment intel-ligència, que en ulls corporals vista» i que «convenia que hom fos pus obedient a intel-ligència que a vista corporal» ${ }^{6} . \mathrm{Al}$ capítol LV: «Car aitant com l' enteniment és pus exalçat a haver coneixença de Déu, d'aitant pus fortment la volentat ha aparellament com s'exalç a molt amar Déu e sos servidors» ${ }^{7}$. Finalment, al capítol LXXXVI, diu: «Lo cardenal de 'Gratias agimus tibi', qui havia rebut l'ofici a honrar la saviea de Déu, estec un dia denant l'apostoli e sos companyons, e dix aquestes paraules: -Natural cosa és que aitant com l'enteniment humà és mills endreçat a entendre Déu, aitant la volentat és pus aparellada a amar Déu e a desamar pecat; e per açò jo deman ofici com pusca tractar que l' humà enteniment sia exalçat a entendre Déu per ço que Déus sia conegut e amat per son poble, lo qual li faça gràcia e beneesca sa glòria-. E l'apostoli e.ls cardenals li donaren l'ofici que demanà» ${ }^{8}$.

Fins aquí, pel que es refereix a la formulació de la primera part del pensament. Però, de fet, en alguns dels capítols del Llibre d'Evast e Aloma e Blaquerna, com el XLIII i, sobretot, el LV, ja s'hi pot observar una construcció molt propera a la formulació de la segona part del pensament lul-lià que estudiem aquí. En efecte, l'expressió «car on pus escura és la semblança, pus altament entén l'enteniment qui aquella semblança entén» és un tipus de construcció ben semblant a «Car aitant com l' enteniment és pus exalçat a haver coneixença de Déu, d'aitant pus fortment la volentat ha aparellament com s'exalç a molt amar Déu e sos servidors». Una construcció que trobem també en el capítol LXXXII del mateix llibre de Blaquerna: «on pus fortment les parts se contrastaven en jutjar qual de tots quatre havia mills loat Déu, pus fortment creixia devoció en les gents qui oïen lo contrast de les parts» ${ }^{9}$. I que ja era també al Libre de doctrina pueril, XXXI, 9: «On més en est món exalçaràs ton enteniment en conèixer i en amar i en servir Déu, major enteniment hauràs, fill, en glòria».

Tanmateix, no és pas només el tipus de construcció sintàctica el que atreu d'aquest paràgraf lul-lià, sinó les paronomàsies, que donen, d'una banda, vivor estilística al discurs i, d'una altra, profunditat i elevació al pensament.

\footnotetext{
5 OE, I, p. 173.

${ }^{6}$ OE, I, p. 189-190.

7 OE, I, p. 190.

8 OE, I, p. 244.

9 OE, I, p. 237.
} 
